\title{
Accept and apply diversity? An exploratory study of the attitudes towards diversity of students of STEM subjects
}

\section{Petia Genkova ${ }^{1}$ (D) $\cdot$ Henrik Schreiber ${ }^{1}$}

Received: 10 June 2020 / Accepted: 13 January 2021 / Published online: 10 February 2021

(c) The Author(s) 2021

\begin{abstract}
German universities are obligated to guarantee a fair learning environment for students with diverse features. They also must prepare students for a highly diverse working environment. This means to develop awareness for diversity and to train intercultural competence. The present study takes an exploratory look at the extent to which diversity awareness is established among science, technology, engineering, and mathematics (STEM) students and which barriers for the academic success students with a migration background perceive. To counteract discrepancies between the current state and the need for diversity awareness at universities, it identifies areas with room for improvement regarding the dealing with cultural diversity. Structured interviews with 31 STEM students were carried out and analyzed using qualitative content analysis. The interviews revealed differences in the awareness of diversity between students with and without a migration background. Results showed that there are barriers for STEM students with migration backgrounds which potentially reduce their academic success. Those barriers result from a lack of acceptance of cultural diversity and insufficient social integration and were especially apparent in insufficient language skills, orientation difficulties, and a lower degree of social integration. On the other hand, there is a need for both students with and without a migration background to promote competence and raise awareness for diversity. Furthermore, the role of social support as a resource became apparent.
\end{abstract}

Keywords Academic success · Diversity · Germany · Intercultural competence · Migration background $\cdot$ STEM

Petia Genkova

petia@genkova.de

1 University of Applied Sciences OsnabrückCaprivistr. 30A, 49076 Osnabrück, Germany 


\section{Introduction}

The term "diversity" has become a catchphrase, which does often not reflect the complexity and connected challenges of the concept. High diversity in various dimensions, which is basically present in every western society, is connected to challenges and chances (Van Knippenberg et al. 2013). However, research indicates that many consider diversity as a threat, especially cultural diversity. In a dynamic social environment, like the workplace or the university, changes connected cultural and ethnic diversity are especially likely to lead to the perception of insecurity or stress. This is strongly associated to a lack of intercultural competence and negative attitudes towards cultural diversity of both people with and without a migration background (Van der Zee and Van Oudenhoven 2013). However, people with a migration background are much more often considered the minority group and stigmatized, which is why they are at a high risk to experience a loss of performance capacity due to intercultural stress (Thomas 2003; Caligiuri 2012; Chen et al. 2012).

Nevertheless, diversity is not only a challenge but creates new chances for societal progress, economic productivity, and innovative abilities. However, Utilizing this positive potential requires a certain level of competence as well as positive diversity attitudes. Moreover, there are indications that people with and without migration background face different challenges regarding the utilization of diversity (Pitts 2009; Van Dick and Stegmann 2016). European universities reacted to the rise of this relatively new topic in social sciences, trying to provide opportunities for students to study abroad and gain intercultural competence (Genkova and Schreiber 2019). Taking the globalized working environment in most jobs into account and in line with the extent of literature on this topic (Krell 2013; Pettigrew 2016; van Dick and Stegmann 2016), we consider positive attitude towards diversity and a high degree of intercultural competence as desirable. However, less attention has been paid to the situation on campus, especially on the situation in certain sectors or subjects. This appears to be a significant gap. As universities are obligated to provide appropriate circumstances for students in order to gain on- and off-topic skills and traits, diversity actions require specific knowledge of perspectives of relevant groups such as students of certain faculties and students with a migration background.

Germany, as well as other European countries, experience a lack of skilled workforce in many sectors, especially in the fields of science, technology, engineering, and mathematics (STEM). The reasons for this lack are related to demographic changes as well as to the inability of the respective education systems to provide a sufficiently skilled workforce (Bundesministerium für Wirtschaft und Energie 2020). This makes STEM students to an especially relevant group for universities to provide competences and prevent disadvantages. In Germany, STEM students show high drop-out rates of $42-54 \%$ of undergraduates who cancel their studies or switch to another program. Moreover, persons with a migration background are significantly more likely to drop out of their studies or to study longer than intended (Neugebauer, Heublein and Daniel 2019). Nevertheless, the public 
discourse about the lack of STEM workforce does not take cultural diversity into account sufficiently, and universities hardly implement diversity issues into the curricula of STEM subjects (Koller and Rudolph 2017; Pletl and Schindler 2007). Moreover, there is a lack of in-depth research on the role of diversity at universities (Neugebauer et al. 2019). It is not clear, in how far STEM students share the insensitive perception of diversity that Koller and Rudolph (2017) describe for the field of STEM studies in general and which role diversity plays for the life of STEM students with and without immigration background. Therefore, the present study takes an exploratory look at the extent to which previous research on diversity attitudes and barriers for people with migration background is in line with the situation of STEM students in Germany. Consequently, two questions arise for this study: Which specific perspectives, attitudes, and competences do the surveyed STEM students have and need in order to be prepared for a globalized working environment? And do the surveyed STEM students with migration background perceive barriers that potentially impede their academic success?

\section{Theoretical background}

In the context of groups, the term "diversity" was originally applied to refer to the diversity of staff in organizations in the United States (Becker 2006). It denotes the extent to which people have salient aspects in common or differ from each other (Krell 2003). In Germany, the dimensions of gender, culture, and age are especially relevant (Krell 2008; Genkova and Ringeisen 2017a, b). STEM studies and practice have always been coined by a particularly high international interconnectedness, which makes cultural diversity to one of the most important dimensions of diversity in this specific field (Koller and Rudolph 2017). Reacting to the strong public attention towards gender diversity of STEM students, universities and other institutions made significant efforts to reduce disadvantages for women in scientific and technical subjects (Auferkorte-Michaelis and Linde 2016; Koller and Rudolph 2017). However, cultural diversity did not receive similar attention, irrespective of the mentioned fact that differences in drop-out rates between those with and without migration background are the biggest in STEM subjects, compared to other fields of study (Neugebauer et al. 2019). When investigating cultural diversity, a definition of the term "culture" is crucial (Genkova and Ringeisen 2017a). Thomas (2003) describes culture as an orientation system that defines membership in society through the perception, thinking, and acting of its members. Furthermore, culture is an aspect of one's social identity (Brewer and Yuki 2007). If an individual leaves the familiar orientation system, he or she may experience that the standards for evaluating a situation and actions are no longer appropriate. Due to the ongoing globalization and diversification of most societies, situations in which individuals are confronted with unfamiliar cultures are increasing. Since individuals often assume that their own orientation system is the right one, such a situation can lead to the perception of stress (Thomas 2003). Despite these difficulties, interaction between people from different cultures can also promote mutual understanding and adaptation to the other culture (Berry 2011). There is strong meta-analytical support that cultural diversity leads to 
increased team and organizational performance, provided that group members have positive attitudes towards diversity (Stegmann 2011). Positive diversity attitudes are defined as the conviction that (cultural) diversity is a benefit for groups (Van Knippenberg and Haslam 2003).This appears to be closely related to the ability to interact with a certain culture appropriately and effectively (Deardorff and Arasaratnam-Smith 2017; Lloyd and Härtel 2010). Those who are more able to interact with another orientation system are more likely to enjoy doing so. This applies to society in general and to educational institutions and companies in particular. Consequently, the question is less whether someone prefers a higher or lower degree of diversity in a certain context, but more whether someone is able to utilize the full potential of the already existing and increasing degree of diversity in organizations, societies, and institutions. This requires positive attitudes as well as certain competences.

Intercultural contact demands and promotes such competence as a condition and consequence of intercultural interaction ( $\mathrm{Ng}$ et al. 2017). Nevertheless, no generally accepted, theoretically sound and empirically proven overall model of intercultural competence currently exists in the literature. A minimum consensus remains that intercultural competence is the ability to act appropriately and effectively in intercultural situations (e.g., Genkova 2019; Deardorff 2006). This ability is characterized by a high level of awareness that cultural differences exist, together with the knowledge and skills to deal with them in a targeted manner (Genkova and Ringeisen 2017a). There is a widely spread agreement that a certain degree of experience with other cultures is necessary to develop intercultural competence (Wolff 2017; Genkova and Schreiber 2019).

Individuals with a migration background are in a special situation, as they are often expected to adapt to the respective host culture, while developing positive attitudes towards diversity (Zick 2010). Thereby, immigrants and people with migration background are likely to not only experience problems due to cultural differences (like subjective stress due to a lack of a sufficient orientation system). Rather they experience even enhanced barriers due to negative attitudes and discriminating behavior and structures in the host country, which might impair them in achieving their aspirations and potentials (Uslucan and Brinkmann 2018). People from minority groups are often subjected to effects from stereotype threat during situations of intergroup interaction. Stereotype threat means that people who are afraid to be assigned to a stereotyped group are less able to perform. If stereotypes are particularly salient (for example, because people are made aware of their own group affiliation), the probability that the performance will be impaired increases (Spencer et al. 2016). Massey and Fischer (2005) investigated the negative effects of a high degree of perceived group differences on the performance of students that belong to a cultural minority. They showed that activating the threat of being stereotyped in the presence of mainstream culture members leads to decreased individual performance. The presence of members of another relevant group is expected to be connected to a certain perception of otherness, which leads to the idea of "them" judging "us." Van Knippenberg et al. (2013) explain this relationship as diversity fault lines, the subjective gaps between groups that lead to a perception of otherness. Uslucan and Brinkmann (2013) and Gutentag, Horenczyk and Tatar (2018), therefore, emphasize the importance of attitudes towards diversity in general to overcome challenges 
connected to diversity. They argue that positive attitudes towards diversity should be linked to worshiping diverse groups and developing an overall identification that includes members of various subgroups. However, they also mention that contextspecific barriers for people with migration background regarding diversity attitudes need to be investigated in order to overcome certain challenges.

\section{Study objectives}

The described approaches of possible disadvantages for students with migration background and required attitudes and competences do not consider the specific situation of STEM subjects. In order to deal with diversity at universities effectively, students' attitudes towards diversity as well as problems and the need for support can function as indicators for a possible need for action. Therefore, this study intends to test to what degree psychological research results on diversity attitudes and barriers, which were corroborated in other contexts, also apply to the case of STEM students. While political discourse and social desirability might bias explicitly expressed opinions towards diversity, the aim of the present study is to examine the implicit attitudes towards diversity of STEM students on the questions which specific perspectives, attitudes, and competences do the surveyed STEM students have and need and whether the surveyed STEM students with migration background perceive barriers that potentially impede their academic success. Therefore, we designed an explorative, qualitative study, and breaking down our leading questions into four main subjects:

1. Are students aware of the relevance of the topic of cultural diversity? B. What are the students' attitudes towards diversity?

2. Do barriers become apparent for students with a migration background?

3. Is there a need for competence development regarding the dealing with diversity?

\section{Method}

\section{Research design}

To provide a holistic picture of the subjective theories (Hilmer 1969) of students, which either belong to the majority culture or to a minority cultural group, on attitudes towards diversity, barriers as well as intercultural competence, we conducted a qualitative explorative Study. We used a semi-structured interview guideline with 47 questions. The researcher who conducted and evaluated the interviews, was a junior research associate with extensive training in methods of qualitative social research.

\section{Recruitment and participants}

The interviews took place between May and July 2019. To ensure a random sample of STEM students and to reduce self-selection, students were randomly approached 
by a researcher on the campus and got interviewed directly. First-year students were excluded due to the short time they had spent on the campus at the point of the study, since it was not expected that these students had sufficient experience with university life.

We interviewed 31 students from the University of Applied Sciences Osnabrück (16) and the University of Osnabrück (15) at the joint science/technical campus. The participants were on average 24 years old, about half of them were male (15) and about half of them female (16; none of the students designated him-/herself as diverse or anything else). Both undergraduate (15) and graduate (16) students studied a STEM subject. About one third of the students had a migration background (eleven) and two thirds none (20). Drawing on Kemper (2010), we defined people with a migration background as those who either immigrated themselves to Germany or whose parents immigrated (i.e., first- and second-generation immigrants). Five of the participants were first-generation immigrants. The others were secondgeneration immigrants. Furthermore, three of the five first-generation immigrants had refugee experience and fled Syria two and four years ago.

\section{Data collection}

First, the participants were informed that the interviews would be recorded. In accordance with the data protection guidelines, they gave written consent that the anonymous records might be used for scientific purposes. The interviews took between 20 and $45 \mathrm{~min}$. In order to reduce or at least expose socially desirable answering, the interview guide contained a mixture of direct questions, semantic differential questions as well as ten direct closed self-assessment questions. The guide was newly created, covering previously identified topics from literature research that have been described above. However, we put a specific focus on aspects, which are relevant for students, such as peer groups, behaviors of friends, professors and university administration, goals and experiences with working life, social support, and academic success. We, therefore, build on findings from previous research in higher education (such as Neugebauer et al. 2019).

As we interviewed both persons with and without a migration background, we had to ensure conceptual equivalence and comparability (cf. Genkova 2019) across the subgroups. Therefore, several experts for diversity and higher education with and without a migration background discussed the finished interview guide and approved it after minor changes. The questions were divided into subtopics, which were diversity in general and the impact of diversity in order to examine awareness and attitudes towards diversity. Additionally, barriers for students with a migration background were explored through the topics of subjectively important individual characteristics, stereotype threat, and fault lines. Finally, questions regarding intercultural competence were asked, assuming that attitudes towards diversity would also be reflected in responses on intercultural 
competence. Optional follow-up questions were included, which could specify the questions when respondents inquired about the meaning of the question, in order to ensure comparability for the later process of category formation. The transcription of the interviews was conducted by student research assistants.

\section{Data analysis}

The inductive analysis of the material followed the qualitative content analysis approach of Mayring (2010). The three steps of qualitative content analysis were conducted using Microsoft Excel. Table 1 displays the steps of paraphrasing, generalization, and categorization as an example for the question "Are the abovementioned special characteristics [related to the cultural background] for studying an advantage or disadvantage or without influence?". Subsequently, the former mentioned group of experts for diversity and higher education discussed the category formation in order to ensure better objectivity as a basis for interpretation. This corresponds to a procedure for triangulation proposed by Bengtsson (2016). Subsequently, the category system was transferred to IBM SPSS in order to create cross tables. We used the category system as unit of analysis, while referring to the transcripts several times in order to ensure methodological integrity. The interpretation was conducted by a mixture of qualitative considerations and quantitative comparisons to support qualitative findings as suggested by ***Krippendorf (2004). Therefore, we compared the categories and answers of individuals and groups, e.g., students who showed different degrees and types of sensitivity towards diversity, for single questions and over the whole interview in order to interpret participants subjective theories sufficiently.

Table 1 Sample question to illustrate the content analysis procedure

\begin{tabular}{ll}
\hline Question & $\begin{array}{l}\text { Are the above-mentioned special characteristics [related to the cultural background] for } \\
\text { studying an advantage or a disadvantage or without influence? }\end{array}$ \\
\hline Answer & $\begin{array}{l}\text { Um, there are definitely disadvantages due to some backgrounds, for example a migra- } \\
\text { tion background makes studying even more difficult, simply because you don't know } \\
\text { the study system here so well and sometimes you are overstrained by the expectations } \\
\text { that are placed on you, especially if you don't know exactly what is expected of you. } \\
\text { Um, otherwise, in terms of age or gender or something like that, not at the moment, } \\
\text { no disadvantages. Um, yes, I think that the essential thing is that you don't know } \\
\text { exactly what is expected of you here }\end{array}$ \\
Paraphrazation & $\begin{array}{r}\text { A migration background can be a disadvantage if you are not familiar with the system } \\
\text { and requirements. I would not consider age or gender as an advantage or disadvantage }\end{array}$ \\
Generalization & $\begin{array}{l}\text { A migration background can be a disadvantage due to knowledge about the system } \\
\text { Categorization }\end{array}$ \\
& A migration background, disadvantage, knowledge about the system
\end{tabular}


Table 2 "What do you personally understand by diversity?" frequencies, multiple answers possible

\begin{tabular}{|c|c|c|c|c|c|}
\hline \multicolumn{3}{|c|}{ No migration background $(\mathrm{N}=20)$} & \multicolumn{3}{|c|}{ Migration background $(\mathrm{N}=11)$} \\
\hline Category & Quantity & Percentage & Categrory & Quantity & Percentage \\
\hline Origin & 5 & $25.00 \%$ & Origin & 5 & $45.00 \%$ \\
\hline Characters & 5 & $25.00 \%$ & Cultures & 4 & $36.40 \%$ \\
\hline Worldviews & 4 & $20.00 \%$ & Social classes & 3 & $27.30 \%$ \\
\hline Cultures & 3 & $15.00 \%$ & Gender & 3 & $27.30 \%$ \\
\hline Acceptance & 3 & $15.30 \%$ & Equality of opportunities & 2 & $18.20 \%$ \\
\hline No idea & 3 & $15.00 \%$ & Race & 1 & $9.10 \%$ \\
\hline Heterogenity & 3 & $15.00 \%$ & Variety & 1 & $9.10 \%$ \\
\hline Social attention & 2 & $10.00 \%$ & Freedom & 1 & $9.10 \%$ \\
\hline Different interests & 2 & $10.00 \%$ & Acceptance & 1 & $9.10 \%$ \\
\hline Bio-diversity & 2 & $10.00 \%$ & & & \\
\hline Exchange of experiences & 1 & $5.00 \%$ & & & \\
\hline Social classes & 1 & $5.00 \%$ & & & \\
\hline Disability & 1 & $5.00 \%$ & & & \\
\hline Race & 1 & $5.00 \%$ & & & \\
\hline
\end{tabular}

Table 3 Subjective significance of the diversity characteristics

\begin{tabular}{lll}
\hline Diversity feature & Mean of relevance & Std. deviation \\
\hline Age & 4.16 & 1.655 \\
Gender & 4.13 & 1.833 \\
Disability & 4.65 & 1.743 \\
Religion/worldview & 4.20 & 1.808 \\
Race/ethnical origin & 4.94 & 2.112 \\
\hline
\end{tabular}

\section{Results}

\section{Question 1 A: Are students aware of the relevance of the topic of diversity?}

The questions about diversity and the impact and handling of diversity were examined in the first question. It became evident that diversity is not a salient topic for the surveyed students. Regarding the question "What do you personally understand by diversity?," ten percent answered that they had no idea of the term diversity at all. About one third mentioned the terms origin or cultures. Table 2 displays the categories for this question sorted by the frequency of appearance. All in all, the surveyed students mentioned a lot of categories. Anyways, most participants were very insecure about this question and gave only one answer, while some students had a more clear idea of what diversity might be. Moreover, students with migration background showed security regarding the dimension of cultural diversity. Except one, all of them mentioned the terms cultures, origins ore race. However, despite the origin topic, most of the students with migration background were comparably 
insecure about dimensions of diversity, showing that they were clearly aware of themselves being relatively different, without being necessarily sensitive to the diversity of others.

In order to determine the relevance of diversity characteristics, the following closed question was asked: "Which of the following characteristics do you think are relevant to diversity? Please rate the importance on a scale from 1 (not important) to 7 (very important)." The categories are shown in Table 3. It became evident that some of the students were surprised by the idea that age, gender, disability, religion/ belief, and racial/ethnic origin should be considered as something important. Students with a migration background rated the significance of the category race/ethnic origin similarly as the students without migration background. However, while the latter showed a high level of variation, students with migration background reported medium to high values more stringently. Statistical analysis showed no significant group differences in the mean values. Regarding the other diversity characteristics, we did not observe any difference between participants with versus without a migration backgrounds, in terms of the quantitative expression of importance. Although special treatment of women in STEM subjects was reported in later parts of the interview, female participants did not rate the gender category differently than male participants.

Seventy percent of those surveyed felt that diversity was insufficiently considered in companies. Anyways, one third of those participants considered diversity in organizations as something negative. Moreover, it was found that students with versus without a migration background answered the questions about society differently. Most of the students without a migration background considered the effort for the consideration of diversity in our society as sufficient (a couple of them mentioned the barrier-free canteen building). In contrast, students with a migration background were mostly convinced that our society does consider diversity not sufficiently.

However, the students responding to this opinion did not report any experiences of racial discrimination in any of the cases, and only three respondents indicated that they had experienced non-linguistic disadvantages due to their cultural background, which referred to the feeling of not fitting in, experiencing a lack of friends, and general uncertainty. As individuals with migration background were much more aware of the topic of diversity and could answer much more differentiated and confident to questions towards problems of diversity and discrimination, we assume that persons with a migration background tend to be more sensitive to diversity and discrimination tendencies.

\section{Question 1 B: What are the students' attitudes towards diversity?}

Regarding the attitudes towards cultural diversity, the following questions were asked: "How is the impact of great diversity in society assessed? How at uversity and in a working group?" In addition, we examined what students perceive as the right way to deal with diversity or what they would recommend to a friend. Moreover, we addressed the quality and object of existing attitudes of the participants. 
Students showed uncertainty particularly on the question how they experience diversity in work-groups. We assumed that students would be especially able to answer this question as it strongly relates to their day-to-day life. Apparently, much of them seemed either to be uncertain about what a "high diversity" means, or whether they are allowed to express the opinion that they preferred more homogenous groups when they had to choose. The phenomenon of social desirability might explain this. Approximately one third of the participants, with and without migration background, expressed the opinion that one should show one's own cultural characteristics only cautiously or not at all, which is considered an indicator for negative implicit attitudes towards diversity. Apparently, this participants showed particularly strong uncertainty about diversity in the beginning of the interview; e.g., one person stated to the question what he would recommend to a friend:

"Something between not paying attention and showing it (cultural characteristics). If it is absolutely necessary that you don't eat meat, pork, then you should do so because of religion. But if it's absolutely necessary to eat pork, then you should do it, because of religion. But if it is something like, hey, check me out, I'm a person of color... (laughing uncertainly)." (translated by the author).

Although many participants without a migration background did not have a clear understanding of the concept of cultural diversity, they were skeptical about diverse working groups and emphasized the need for particularly good communication. One third of the participants believed that diversity only has a positive effect on the group result if there is good communication. One person without a migration background explicitly stated that he or she considered cultural differences in general to be nonexisting (e.g. "we are all pretty much the same"), but that "there are a few values that just have to be adhered to here [...]." This attitude seemed to be shared by some of the interviewees, implicitly or explicitly problematizing the issue.

Regarding dealing with diversity in the context of the university, a large proportion of the students believed that diversity at the university was something positive and that a lot was already being done for it. In some cases (10\%), there was talk of doing too much, even though previous answers indicated that they worship diversity in general. Apparently, implicit attitudes strongly differed here. These students showed low awareness of diversity but obviously perceived that the issue is of high importance. It is reasonable to assume that without personal experience with diversity, the topic is more likely to become problematic. Separate attitudes accompanied this occasionally. On the one hand, this could refer to the so-called modern prejudices. These are characterized by socially desirable observable behavior, while subtle prejudices are being held. Modern prejudices lead to discrimination by a preference for separation ("I have nothing against them, but...") On the other hand, some of the persons obviously did not perceive the complexity or the social implications of these phenomena. From a professional point of view, the surveyed STEM students without migration background are not familiar with diversity concepts and social psychological theories. This is likely to be either connected to a problematization or trivialization of diversity.

Persons with a migration background reported more positive diversity attitudes overall. At the same time, they repeatedly reported problems such as language 
barriers, acculturation problems, and the challenge of unfamiliar environments. Among most participants, a higher awareness of cultural diversity was accompanied by a positive attitude towards it, which fits the current literature on diversity attitudes and awareness (e.g., Van Dick and Stegmann 2016). However, some students, including those with a migration background, showed a high level of awareness in combination with a negative attitude towards diversity. It seems that an awareness of problems caused by cultural diversity have been developed which results in the attitude that homogeneous groups work and live better.

\section{Question 2: Do barriers become apparent for students with a migration background?}

In order to determine how differently students perceive themselves compared to others 14 short questions followed on whether, and if so, how strongly the students perceived themselves to differ from their environment. It turned out that the most frequently selected categories were language and type of communication (8 mentions), leisure activities (7), educational background (7) and ethnic background (7), and migration background / experience (6). Differences in language were only reported in three cases and referred to the presence of an accent. Those who thought they were different perceived themselves as more polite and as more appropriate in their way of communication than their environment. This can be attributed to the high educational level of the sample. With regard to leisure activities, three participants stated that they migrated to Germany and that the leisure activities here differed from those in their home country. For this reason, in addition to a certain lack of orientation on campus, it took them some time to find their way around.

The question "What common ground do you see within your circle of friends?" was intended to show whether students perceive intergroup differences. Participants without a migration background stated that their main interests and attitudes were the same as those of the group of their friends and that they had common interests and attitudes. Among persons with a migration background, the main commonalities with their group of friends were origin, studying the same subject and leisure activities. There was a strong consensus between most of the participants with migration background that their migrant friends do understand their thoughts and problems, such as the ambiguity between the parents and the German culture, much better. The next question was "Would you say that all students are treated equally by teachers?" Surprisingly 12 people answered with a no. Three of them said that they were treated better because they are female. No evidence for racial discrimination by the lecturers was found in this study. Considering the question on whether participants would recommend to show their cultural differentness to others, it became apparent that the participants with second-generation migration background were not being discriminated in a meaning of negative behavior, rather than showing a low selfesteem regarding their migration background.

Overall, the students hardly showed any signs of stereotype threat. Some interviewees with a migration background assumed that they would have a harder time on the labor market. Above all, this seemed to be associated with a strong 
problem awareness and limited knowledge of the national language. They stated that if their German is not good enough, they will not be able to find a job. This is illustrated by the fact that four of the persons with migration experience could not speak German language at all. The perceived threat seemed to stem less from potential stereotyping than from the concern about not speaking German well enough. Nevertheless, students with migration experience seemed to take it for granted that they would adapt. It was considered necessary to speak German as a prerequisite for finding social connection at the university which was relatively important for the students.

It can be assumed that a high degree of willingness to integrate led to a different perception of group differences and a lower tendency to perceive stereotypical threats. Conversely, this would mean that people with less motivation to integrate would be more likely to feel a corresponding threat by attributing negative characteristics to this outgroup.

It could be shown that students with a migration background do not feel directly excluded but do perceive fault lines between themselves and others. However, the participants without a migration background did not perceived any of them. The students with a migration background also showed a higher awareness of problems related to intercultural contact, like language and orientation, as well as fault lines. In the case of first-generation migrants, the aspects of integration and acculturation appeared: "I have a different religion than here. - Very different."; "I have to search a lot. More than the others or question more. - It is like I said, I don't know the system, so I have to understand it first and then I can say or do something about it."

Individuals who are already studying at a university obviously have already achieved a certain degree of psychological adaptation. Remarkably, only the Swiss participant reported problems of psychological adjustment, loneliness, and the feeling of being very different from his/her environment which has contradicted his/her expectations. The other persons with a migration background reported strikingly more often that their family is more important to them than students with a minority cultural background. It is obvious that a culturally anchored high value of family tends to contribute to the fact that students with a migration background do not feel left alone in their studies.

In summary, the interviewed STEM students with a migration background reported particular language barriers as well as orientation difficulties on campus and in private life. Most individuals with a migration background had smaller circles of friends. Fault lines emerged in this study primarily through the fact that persons with a migration background perceived themselves as different from their overall environment in some isolated aspects and less through the distinction between persons with and without a migration background. The threat of stereotypes did not play a major role for the surveyed students. There are indications that this is related to a high degree of willingness or perceived need to adapt. Further, the students with migration experience holding their family in high esteem did not report that they experienced problems with orientation but with regard to the language. Therefore, the presence of the family (which is not self-evident, especially in the case of refugees) and its importance might be a resource for overcoming barriers. 


\section{Question 3: Is there a need for competence development regarding diversity?}

To capture the subjective theory about the participants' own intercultural competence, respondents were asked to rate themselves on a scale of one to seven on how well they could deal with other cultures. Almost all participants indicated at least five out of seven and thus rated themselves as competent. This is outstanding, as most participants had a moderately pronounced awareness of cultural diversity in their own society, and most of the individuals without a migration background had no persons with a migration background in their circle of friends. At the same time, these students assumed that they could interact well with other cultures. In order to get a better understanding of what exactly constitutes intercultural competence for the participants, the questions asked, and answers given can be seen in Table 4. Participants had few concrete ideas on how intercultural competence could be acquired. The most participants mentioned general openness and language skills as necessary skills and general intercultural experiences as relevant experiences. However, few of them could give concrete examples or reasons for the relevance of this dimensions. Differences between students with and first and second-generation migration background became apparent. The first-generation migrants expressed their belief that the processing of cultural differences, understanding and reacting appropriately, were the most important dimensions. The second-generation migrants mentioned repeatedly that dealing with the ambiguity of cultures and worshiping diversity. Moreover, some of the second-generation migrants expressed that they do not believe in cultural differences and that language is the only problem in intercultural interaction. This provides another indicator for the observation that a large proportion of the respondents is not aware of the challenges of intercultural contact.

\section{Discussion}

\section{Diversity attitudes}

With the study at hand, we intended to test to what degree previous findings on diversity attitudes and barriers in education are in line with the experiences of STEM students. The aim is to identity fields for further study and possible points for interventions by universities. In the analysis, differences in the perception of diversity were found between students with and students without a migration background. The perception of diversity among students without a migration background (and without the experience of prolonged stays abroad) was often characterized by a low degree of elaboration regarding implications of diversity, not having developed an understanding of possibly involved problems and opportunities. This was often coined by underlining the importance of diversity on a general level at first but showing a tendency to see diversity as a problem, which became apparent in their views on diversity in society, companies, and working groups. Students without a migration background but with the experience of a semester abroad or internal migration were more aware of the issue of diversity and showed less uncertainty. 


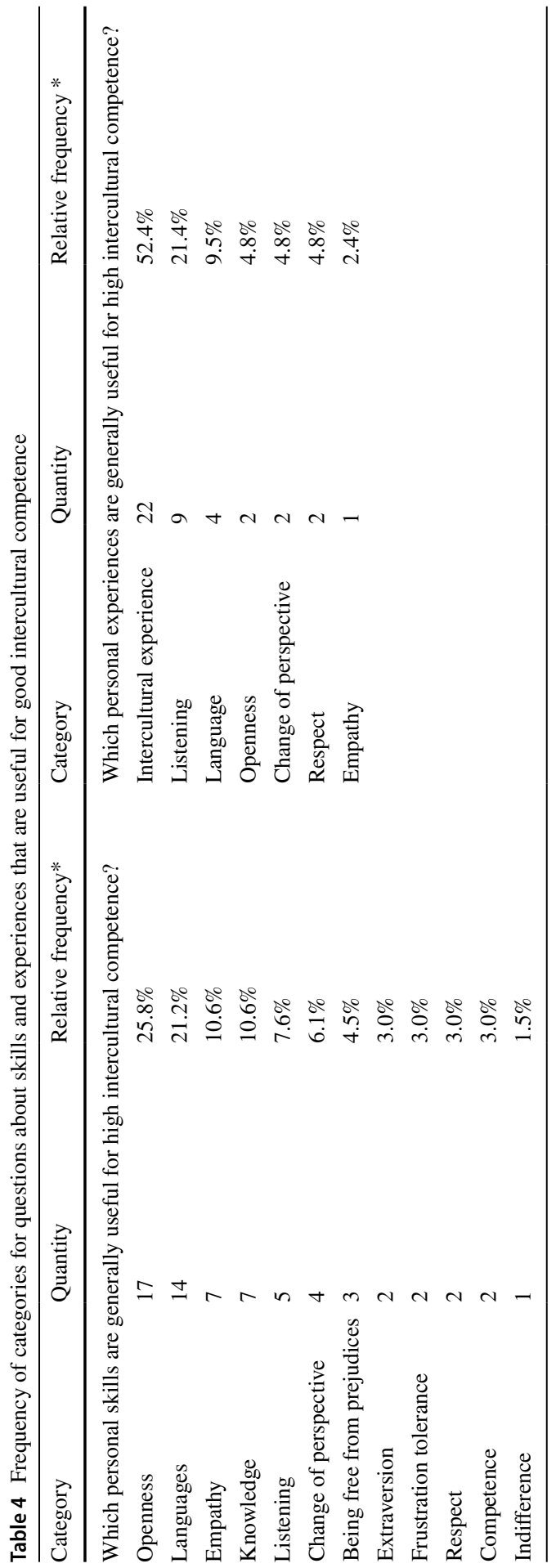


The results suggest that a lower awareness of diversity in students day-to-day environment leads to more negative implicit attitudes. The contact hypothesis, according to which a greater degree of intergroup contact leads to a reduction in mutual prejudices (cf. Pettigrew and Tropp 2005), might explain the proportion of people without a migrant background who have a negative attitude towards diversity. However, the students surveyed do not seem to have negative prejudices about outgroups rather than being uncertain about how to deal with otherness. Among the interviewees who were more aware of the issue, some (with and without a migration background) showed mistrust regarding a high level of cultural diversity. This could reflect a culture-blind perspective that assumes that there are no cultural differences (e.g. Gekova 2019). Gutentag et al. (2019) showed the negative effects of such an undifferentiated perspective on the ability of teachers to teach in multicultural classrooms. According to Genkova (2019), such a perspective corresponds to the Absolutism Paradigm (former Colonial Paradigm) and an ethnocentric perspective of American-influenced psychology. Some respondents seemed to perceive the issue of diversity relatively often together with its social implications leading to a feeling of uncertainty about how to appropriately deal with diversity. The term overstimulation seems to fit here as an expression of modern, subtle prejudices (Pettigrew and Meertens 1995) associated with an implicit negative attitude, due to insecurity about social norms a lack of reliable information. Various studies (Guimond et al. 2013; Stegmann 2011; Uenal 2016; van Knippenberg et al. 2004) show a relationship between uncertainty about diversity, resulting from awareness of importance together with a lack of trustworthy, comprehensible information on the topic. Neither the aware nor the unaware participants of this study ever participated in a diversity training. This also fits the devaluation of the use of resources for diversity issues explained by trivializing cultural differences. Stellmacher and Petzel (2005) expanded this perspective, emphasizing that individual differences in diversity attitudes might stem from individual value predispositions that influences the way we deal with diversity-related uncertainty.

\section{Barriers for students with migration background}

The investigation of the second question showed that language barriers were particularly important for students with migration experience, as were orientation difficulties on campus and in their private lives. People with a migration background tended to report smaller circles of friends, which were often coined by a common migration background. A higher level of social support by family members might compensate for this. The perception of fault lines was only reported insofar as individuals with a migration background perceived themselves as different from their overall environment (i.e., by group-specific attitudes or values) and less by distinguishing between persons with and without a migration background. Anyways, participants reported that dealing with the ambiguity of cultures is a relevant issue for both firstand second-generation migrants. Those of the interviewees with migration experience who described that their families were particularly important (6), reported less of problems with orientation. This was interpreted as indicating that strong family 
ties contribute to resilience. Some respondents attributed the strength of family ties to cultural differences. Moreover, students who reported problems in dealing with ambiguity showed low self-esteem regarding cultural diversity. Consequently, most of the migrant STEM students were aware of the issue of diversity, but some of them were living in an environment, which was not sensitive towards their perception, except their circles of friends and families. Studies from a performance-oriented perspective (Cox 1991; Skrobanek 2007) show the destructive character of such attitudes for the performance of individuals and groups in a culturally diverse environment from. Moreover, the broad studies of Uslucan (2017) on Turkish migrants in Germany demonstrated the negative consequences of such an insensitive environment for migrants. They showed how even those migrants who live in Germany for more than thirty years felt seriously insecure about rules of living in Germany and about having mostly Turkish circles of friends. The results of this study could only partly replicate the results of Uslucan (2017) regarding integration. While he emphasizes discrimination experiences and insecurity as the main source of integration problems, this study took place in a more or less migration friendly environment. On the one hand, at least none of the participants gave reason to believe that there were strong discriminating tendencies in the daily life on campus. On the other hand, there were indications that the insensitivity of their social and professional environment at university leads to such low self-esteem and stronger adaption rather than to deficits in performance. The reason that the results differ from those of Uslucan (2017) might be that the surveyed students were already strongly pre-selected, as they represent a particularly strongly performance-oriented and competent subpopulation from the group of migrants in Germany, while Uslucan (2017) conducted studies with a variety of migrants with different socio-economic backgrounds. One might assume that such performance-oriented and competent students do not need support, but this study does not depicture those students who did not make it to this point, being sorted out during school or dropping out during the first year of studying. Moreover, the result that some of the participants did not feel understood rather than not understanding their environment indicates a potential need to increase the diversity culture in the surveyed organizations. Auferkorte-Michaelis and Linde (2018) outline socio-economic fairness as one of the biggest problems in the German higher education system. This study found differing results; however, we mostly focused on social attitudes and did not consider, e.g., dropped out students. Anyways, Auferkorte-Michaelis and Linde (2018) describe many ways to promote diversity in universities. As presenting their whole concept would exceed the scope of this manuscript, we will only present one point, which is particularly important to the topic of this paper. Auferkorte-Michaelis and Linde (2018) describe that offering opportunities to gain concrete knowledge on issues of diversity, preferably using intercultural contact formats, can lead to both, an increase sensitivity for diversity and less negative attitudes as well as an increased self-esteem regarding the own cultural background (see also Earley and Peterson 2004). Future quantitative studies should, therefore, investigate whether the STEM student's diversity awareness and their attitudes towards diversity might be predicted by the consideration of diversity in the curricula, respectively. 
However, some of the students with migration background reported a fundamentally different perspective, expressing that they do not believe in cultural differences. They stated that despite language, there should be no significant problems in dealing with another culture and they did not strongly identify with their parents culture. Uslucan (2017) describes that especially young second-generation migrants might negate cultural differences and come to a negative perspective on cultural diversity. He emphasizes that this mostly depends on the social environment. Results of this study indicate that those participants were integrated somehow differently compared to the ones described above. According to Berry (2011), they refer to an assimilation strategy of adaption. Samnani et al. (2013) argue reasonably that the acculturation strategy, however, depends on the salience of cultural identity, the relational pressure, and the desire for economic reward. While the study at hand did not investigate those predictors in detail, we can assume that a certain degree of desire for economic reward is given. Moreover, the result of the first question indicate an at least mediocre salience of cultural identity. Samnani et al. (2013) explain that this process explains later economic success of migrants together with moderating social environment variables. However, they do not consider social attitudes as a consequence of a certain adaption behavior. The results of this study imply that either a strongly assimilating pattern leads to worse attitudes towards cultural diversity, or, which is more likely, the conviction that cultural diversity is an impediment for performance leads to a more assimilating acculturation style in order to increase likelihood to succeed. The strong statistical evidence that social attitudes depend on the perceived social environment (Guimond et al. 2013) leads to the question whether those students with migration background and negative attitudes towards cultural diversity overtook this perspective in university or during school. This should also contribute to the third topic of this study, the intercultural competence.

\section{Intercultural competence}

Regarding the third question, the results manifest the impression that some participants were thinking frequently and little differentiated about intercultural interactions. Some of the participants, including some without a migration background, viewed language as the central problem concerning intercultural contact. The latest research results show that language has an influence on intercultural competence but cannot explain it completely (Genkova 2019). Moreover, language-learning opportunities are already widely available and integrated into curricula at universities (Auferkorte-Michaelis and Linde 2016). Therefore, we consider language skills to be not the central problem of intercultural communication among the students surveyed. However, the results raise the question how students can be not aware of or uncertain about diversity in a sector which is characterized by international mobility. How can they experience a lack of information on diversity? We found that none of the students ever participated in any kind of diversity-related workshop, seminar, or similar development measures. Furthermore, a lot of the participants without a migration background had no migrant friends, and neither considered migration background as a relevant characteristic of their peer group in relation to other 
groups. To sum up, some of the participants hardly had meaningful interaction with people from cultural minorities. This does not seem to be related to explicit negative group norms, or active rejection of a certain group (e.g., refugees), rather than to actually not having information on the topic.

In the social psychology literature, there is strong scientific support for the contact hypothesis (Allport et al. 1954), indicating that intergroup contact reduces intergroup bias, under the condition of common goals and meaningful interaction (Pettigrew 2016). Even though individuals strive to befriend those who are similar to them, there are various opportunities for universities to create intergroup contact, such as diversity seminars (which are pointing to the economic value of diversity) or intercultural mentoring programs. Those are measures which are well established in European universities in social and economic subjects (Claeys-Kulik et al. 2019). However, at least the participants of this study were not aware of such opportunities. Despite the opportunity to sensitize students accordingly, as discussed above, studies reveal that a positive diversity culture needs to be implemented top-down (Genkova 2019). Future studies should, therefore, assess the diversity attitudes of lecturers in STEM subject in relation to their students' attitudes. As mentioned above, Auferkorte-Michaelis and Linde (2018) offer many hands-on-opportunities to increase a faculties' diversity culture.

\section{Limitations}

There are some limitations to this study regarding the sample and the methodology. As we investigated students from two institutions in Osnabrück, the results are not generalizable for social or economic science or for different universities. Furthermore, subjects in certain sector are usually not homogeneous across universities, as context variables and curricula differ, which also limits the generalizability. Consequently, it is only possible to state that the results should be corroborated by larger and more comprehensive samples. Regarding the objectivity of the method, it should be noted that a single person carried out the analysis, supported by several experts though. Although the researcher was a skilled scientist, he conducted main parts of the analysis and the objectivity is, therefore, naturally restricted. As the results of this study are presented using quantitative terminology, one might get distracted regarding the applied methodology. Anyways, quantitative evaluation of data is always meant to support or underline qualitative argumentation, which is a valid method according to Mayring (2010). The argumentation is in no way meant to imply representativity of results.

Considering the literature on the formation of attitudes in combination with our results on diversity attitudes and organizational culture, we assume that the derived results have value for a broader international audience. STEM subjects are characterized by stereotype of being male, anti-social, and focused on technical aspects in a lot of countries (Koller and Rudolph 2017). Pertinent for the literature on diversity management at universities are the findings that there is a lack of sufficient information sources for our participants, like diversity seminars or forums for an exchange of experiences. Furthermore, there was no organizational orientation 
system regarding norms and values towards diversity. We suggest to check the three domains of organizational circumstances, sector-specific stereotypes, and the perception of diversity for other countries in order to create comparable results.

\section{Conclusion}

The survey revealed differences in the awareness of diversity between students with and students without a migration background. Those students who were little aware of the issue seemed to have a tendency towards negative attitudes towards cultural diversity. Those students aware of the topic showed an ambivalent picture. Some of these students who were aware of diversity had ideas on how to deal with it in a meaningful way. Another part of them, however, showed a rather negative attitude, which seemed to partly result from bad experiences, and partly from being over-burdened by the complex, politically charged issue. This is linked to a need to promote intercultural competence among STEM students accordingly. Intercultural competence relates to the sensitivity for cultural difference and knowledge about intercultural interactions (Deardorff 2006; Van Dyne et al. 2008). For future studies, aspects of cultural competence and the possibility of corresponding trainings should be investigated, especially regarding how intercultural competence is developed among students and how this affects future employment. Further, we revealed that barriers for students with a migration background were apparent in language, orientation, and social integration. The role of social support as a resource also became conspicuous. For higher education, this pointed to the possibility of introducing interactionoriented seminar or training designs, to foster intercultural contact. We conclude that awareness raising for diversity issues within the framework of the teaching program for STEM students could help to prepare students for the diverse, globalized world of work and decrease barriers for individuals with migration background.

Funding Open Access funding enabled and organized by Projekt DEAL.. The authors of this manuscript confirm that there is no received funding.

Data Availability Data are available on reasonable request.

\section{Compliance with ethical standards}

Conflict of interest: No conflict of interest to disclose.

Open Access This article is licensed under a Creative Commons Attribution 4.0 International License, which permits use, sharing, adaptation, distribution and reproduction in any medium or format, as long as you give appropriate credit to the original author(s) and the source, provide a link to the Creative Commons licence, and indicate if changes were made. The images or other third party material in this article are included in the article's Creative Commons licence, unless indicated otherwise in a credit line to the material. If material is not included in the article's Creative Commons licence and your intended use is not permitted by statutory regulation or exceeds the permitted use, you will need to obtain permission directly from the copyright holder. To view a copy of this licence, visit http://creativecommons.org/ licenses/by/4.0/. 


\section{References}

Allport GW, Kenneth C, Tettugrew T (1954) The nature of prejudice: Unabridge. Addison-Wesley, Reading

Auferkorte-Michaelis N, Linde F (2016) Diversity Management an Hochschulen. In: Genkova P, Ringeisen T (eds) Handbuch Diversity Kompetenz. Springer Fachmedien, Wiesbaden, pp 803-817

Auferkorte-Michaelis N, Linde F (eds) (2018) Diversität lernen und lehren: Ein Hochschulbuch. Verlag Barbara Budrich, Opladen

Becker M (2006) Wissenschaftstheoretische Grundlagen des Diversity Management. In Becker M, Seidel A (ed), Diversity Management - Unternehmens- und Personalpolitik der Vielfalt. Poeschel Stuttgart. pp 3-48.

Bengtsson M (2016) How to plan and perform a qualitative study using content analysis. NursingPlus Open 2:8-14

Berry JW (2011) Cross-cultural psychology research and application. Cambridge University Press, Cambridge

Brewer MB, Yuki M (2007) Culture and social identity. In: Kitayama S Cohen D (eds) Handbook of cultural psychology. Guilford Press, New York, pp 307-321

Bundesministerium für Wirtschaft und Energie (2020) Fachkräfte für Deutschland. Retrieved from https://www.bmwi.de/Redaktion/DE/Dossier/fachkraeftesicherung.html

Caligiuri P (2012) Cultural agility: building a pipeline of successful global professionals. Wiley, Hoboken

Chen X, Liu D, Portnoy R (2012) A multilevel investigation of motivational cultural intelligence, organizational diversity climate, and cultural sales: Evidence from U.S. real estate firms. J Appl Psychol 97(1):93-106

Claeys-Kulik A, Jørgensen TE, Stöber H (2019) diversity equity and inclusion in european higher education institutions. Retrieved from https://eua.eu/downloads/publications/web_diversity\%20 equity $\% 20$ and $\% 20$ inclusion $\% 20 \mathrm{in} \% 20$ european $\% 20$ higher $\% 20$ education $\% 20$ institutions.pdf

Cox T (1991) The multicultural organization. AMP 5:34-47. https://doi.org/10.5465/ AME.1991.4274675

Deardorff DK (2006) Identification and assessment of intercultural competence as a student outcome of internationalization. J Stud Int Educ 10(3):241-266

Deardorff DK, Arasaratnam-Smith LA (eds) (2017) Intercultural competence in higher education: International approaches, assessment and application, 1st edn. Internationalization in higher education series. Routledge, New York

Earley PC, Peterson RS (2004) The elusive cultural chameleon: cultural intelligence as a new approach to intercultural training for the global manager. AMLE 3:100-115. https://doi. org/10.5465/amle.2004.12436826

Genkova P (2019) Diversity und Diversity Management. In: Genkova P (ed) Interkulturelle Wirtschaftspsychologie. Springer, Berlin, pp 351-364

Genkova P, Ringeisen T (2017a) Handbuch Diversity Kompetenz. Band 1: Perspektiven und Anwendungsfelder. Springer Fachmedien, Wiesbaden

Genkova P, Ringeisen T (2017b) Handbuch Diversity Kompetenz. Band 2: Gegenstandsbereiche. Springer Fachmedien, Wiesbaden

Genkova P, Schreiber H (2019) Impact of stays abroad on intercultural competence of students. In IACCM-IÉSEG Research Conference 2019 (pp 80-102). https://philippepierre.com/website/wpcontent/uploads/2020/01/1-IACCM-IESEG-Conference-Proceedings-2019-okok.pdf\#page=80

Guimond S, Crisp RJ, de Oliveira P, Kamiejski R, Kteily N, Kuepper B, Lalonde RN, Levin S, Pratto F, Tougas F, Sidanius J, Zick A (2013) Diversity policy, social dominance, and intergroup relations: predicting prejudice in changing social and political contexts. J Pers Soc Psychol 104:941958. https://doi.org/10.1037/a0032069

Gutentag T, Horenczyk G, Tatar M (2018) Teachers' approaches toward cultural diversity predict diversity-related burnout and self-efficacy. J Teach Educ 69(4):408-419

Hilmer J (1969) Grundzüge einer pädagogischen Theorie der Bewegungsspiele: ein Beitrag zur Didaktik der Leibeserziehung. Schroedel, Hannover

Institut der deutschen Wirtschaft Köln (2017) Mehr interkulturelle Vielfalt in der Arbeitswelt. Retrieved, December 14, 2017, from https://www.bmfsfj.de/bmfsfj/aktuelles/alle-meldungen/ mehr-interkulturelle-vielfalt-in-der-arbeitswelt/114276 
Kemper T (2010) Migrationshintergrund-eine Frage der Definition. Die deutsche Schule 102(4):315-326

Koller K, Rudolph C (eds) (2017) Gender Mainstreaming und Diversity in der (akademischen) MINTWeiterbildung: Konzepte, Prozesse und Befunde. OTHmind-BMBF-Verbundprojekt

Krell G (2008) Chancengleichheit durch Personalpolitik. Gleichstellung von Frauen und Männern in Unternehmen und Verwaltungen. Rechtliche Regelungen - Problemanalysen - Lösungen. SpringerLink, Cham

Krell G (2003) Personelle Vielfalt in Organisationen als Herausforderung für Forschung und Praxis. In: Wächter H, Vedder G, Führing M (eds) Personelle Vielfalt in Organisationen. Mering, München. pp 219-232

Krell G (2013) Vielfältige Perspektiven auf Diversity: Erkunden, enthüllen, erzeugen. In: Schmidbaur M, Wolde A, Bender S-F (eds) Diversity entdecken. Reichweiten und Grenzen von Diversity Policies an Hochschulen, Beltz Juventa, Weinheim, pp 61-78

Krippendorff K (2004) Content analysis: an introduction to its methodology. Sage, Thousand Oaks

Lloyd S, Härtel C (2010) Intercultural competencies for culturally diverse work teams. J Manag Psych 25:845-875. https://doi.org/10.1108/02683941011089125

Massey DS, Fischer MJ (2005) Stereotype threat and academic performance: new findings from a racially diverse sample of college freshmen. Du bois Rev 2(1):45-67

Mayring P (2010) Qualitative Inhaltsanalyse. Handbuch qualitative Forschung in der Psychologie. VS Verlag für Sozialwissenschaften, Wiesbaden, pp 601-613

Milliken FJ, Martins LL (1996) Searching for common threads: understanding the multiple effects of diversity in organizational groups. Acad Manag 21(2):402-433

Neugebauer M, Heublein U, Daniel A (2019) Studienabbruch in Deutschland: Ausmaß, Ursachen, Folgen, Präventionsmöglichkeiten. Z Erziehungswiss 22:1025-1046. https://doi.org/10.1007/ s11618-019-00904-1

Ng TK, Wang KWC, Chan W (2017) Acculturation and cross-cultural adaptation: the moderating role of social support. Int J Intercult Relat 59:19-30

Pettigrew TF (2016) In pursuit of three theories: authoritarianism, relative deprivation, and intergroup contact. Annu Rev Psychol 67:1-21. https://doi.org/10.1146/annurev-psych-122414-033327

Pettigrew TF, Meertens RW (1995) Subtle and blatant prejudice in western Europe. European Journal of Social Psychology 25(1):57-75. https://doi.org/10.1002/ejsp.2420250106?casa_token =nMUh1Q9s944AAAAA:I7vyRe6dUkJjwsbQDe2zseI_9tQ9UOGBPQB1KdW_-zYfjPtL2aN 88Q1Bb9nWSTyNHECHPQqHyX9qDeo

Pettigrew TF, Tropp LR (ed) (2005) Allport's intergroup contact hypothesis: its history and influence. In: On the nature of prejudice: fifty years after Allport. pp 262-277

Pitts D (2009) Diversity management, job satisfaction, and performance: evidence from US federal agencies. Public Admin Rev 69(2):328-338

Pletl R, Schindler G (2007) Umsetzung des Bologna Prozesses. Hochschulentwicklung/-politik:32-38

Rosenthal L, Levy SR, Katser M, Bazile C (2015) Polyculturalism and attitudes toward Muslim Americans. Peace and Conflict. J Peace Psychol 21(4):535-556

Samnani AK, Boekhorst JA, Harrison JA (2013) The acculturation process: antecedents, strategies, and outcomes. J Occup Org Psychol 86(2):166-183 https://doi/pdf/https://doi.org/10.1111/ joop. 12012

Sidanius J, Cotterill S, Sheehy-Skeffington J, Kteily N, Carvacho H (2017) Social dominance theory: Explorations in the psychology of oppression. In: Sibley CG, Barlow FK (ed) The Cambridge handbook of the psychology of prejudice. Cambridge University Press, Cambridge. pp 149-187 https://doi.org/https://doi.org/10.1017/9781316161579.008

Spencer SJ, Logel C, Davies PG (2016) Stereotype threat. Annu Rev Psychol 67:415-437

Skrobanek J (2007) Wahrgenommene Diskriminierung und (Re)Ethnisierung bei Jugendlichen mit türkischem Migrationshintergrund und jungen Aussiedlern. Beltz Juventa, Weinheim

Stegmann S (2011) Engaging with diversity of social units. Frankfurt am Main, Johann Wolfgang Goethe-Univ., Diss., 2011, Univ.-Bibliothek Frankfurt am Main

Stellmacher J, Petzel T (2005) Authoritarianism as a group phenomenon. Political psychology, pp 252-274

Thomas A (2003) Psychologie interkulturellen Lernens und Handelns. In Thomas A (ed) Kulturvergleichende psychologie. Hogrefe, Göttingen 
Uenal F (2016) Disentangling Islamophobia: The differential effects of symbolic, realistic, and terroristic threat perceptions as mediators between social dominance orientation and Islamophobia. https://doi.org/https://doi.org/10.23668/psycharchives.1691

Uslucan H-H (2017) Diskriminierungserfahrungen türkeistämmiger Zuwanderer_innen. In: Fereidooni K, El M (eds) Rassismuskritik und Widerstandsformen. Springer VS, Wiesbaden, pp 129-141

Van Dick R, Stegmann S (2016) Diversity, Social Identity und Diversitätsüberzeugungen. In: Genkova P, Ringeisen T (eds) Handbuch Diversity Kompetenz. Springer Fachmedien Wiesbaden, Wiesbaden, pp 3-15

Van der Zee K, Van Oudenhoven JP (2013) Culture shock or challenge? The role of personality as a determinant of intercultural competence. J Cross Cult Psychol 44(6):928-940

Van Dyne L, Ang S, Koh C (2008) Development and validation of the CQS. In: Ang S, Van Dyne L (eds) Handbook of cultural intelligence: theory, measurement, and applications. Sharpe, New York

Van Knippenberg D, Haslam SA, Platow MJ (2004) Unity through diversity: value-in-diversity beliefs, work group diversity, and group identification. Group Dyn Theory Res Pract 11:207-222. https:// doi.org/10.1037/1089-2699.11.3.207

Wolff F (2017) Interkulturelle Kompetenz durch Auslandsaufenthalte. Längsschnittanalyse der Wirkung dreimonatiger Auslandserfahrungen, Springer, Wiesbaden

Zick A (2010) Psychologie der Akkulturation: Neufassung eines Forschungsbereiches. Springer, Heidelberg 